\title{
AiMT
}

Advances in Military Technology

Vol. 15, No. 1, 2020, pp. 137-148

ISSN 1802-2308, eISSN 2533-4123

DOI 10.3849/aimt.01327

\section{Interior Ballistics of Amphibious Rifle when Firing under Water}

\author{
P. Konečný ${ }^{1 *}$, V.D. Dao ${ }^{2}$, V.H. Nguyen ${ }^{2}$ and H.B. Le ${ }^{1}$ \\ ${ }^{1}$ Department of Weapons and Ammunition, University of Defence in Brno, Czech Republic \\ ${ }^{2}$ Department of Weapons, Le Quy Don Technical University, Ha Noi, Viet Nam
}

The manuscript was received on 4 April 2019 and was accepted after revision for publication as research paper on 12 March 2020.

\begin{abstract}
:
The paper deals with an adaptation of the standard interior ballistics model for the case of amphibious rifle shooting ammunition under water. The adapted mathematical model was validated and experimentally verified using the $5.56 \mathrm{~mm}$ underwater projectile shot from the $5.56 \mathrm{~mm}$ amphibious rifle. The dependence of the underwater interior ballistic processes on the powder mass was investigated. The results of theoretical mathematic model solution correspond very well with experiment. The described mathematical model and the dependence of the underwater interior ballistic processes on the powder mass can be a reference for designers in the design process of the underwater ammunition or underwater rifle.
\end{abstract}

\section{Keywords:}

amphibious rifle, interior ballistics, underwater ammunition, underwater interior ballistics, underwater projectile

\section{Introduction}

The amphibious rifles are based on the fundamental principle of a gas-operated automatic mechanism [1] and are often designed for use in two environments (water and air). For ensuring the performance and accuracy of the firing process, then the prediction of interior ballistic performance plays a very important role in the ammunition and amphibious rifle design. While the interior ballistic process of amphibious rifles when shooting in the air has been researched and published widely, then the results of the interior ballistic process of amphibious rifles research when shooting underwater are published partially only. A research of the underwater interior ballistic performance is presented in [2], however this research has not been interested in the energy

\footnotetext{
* Corresponding author: Department of Weapons and Ammunition, University of Defence in Brno, Kounicova 156/65, CZ-662 10 Brno, Czech Republic. Phone: +420 973442 037, E-mail: pavel.konecny@unob.cz
} 
conservation equation when shooting under-water. Besides, experimental studies are still incomplete. It is the reason for the need of the more in-depth research on this issue. On the other hand, in the trend of weapons technology development, the types of ammunition are often modified to match the available weapons for different combat conditions, so researches of the dependence of interior ballistic process on the ballistic characteristics of the cartridge (it means the projectile mass and powder mass here) also has an important meaning.

In comparison with the standard interior ballistics of automatic rifle valid for air, which uses gas-operated principle [3], the underwater interior ballistics is different. Its biggest difference is in the projectile being in the water inside the barrel bore when the density and viscosity of water are greater than the density and viscosity of the air. In addition, the projectile during its movement ejects the amount of water inside the barrel and changes the water mass. So, it is difficult to calculate it by the model of the standard interior ballistics in air.

For the prediction of amphibious rifle interior ballistic performance when shooting underwater, the paper improves the standard interior ballistic model for air into an interior ballistic model used for shooting underwater and applies it to calculate the case of firing projectiles $5.56 \mathrm{~mm}$. Some calculation results are compared with experiments to validate the improved interior ballistic model.

\section{Mathematical Model of Interior Ballistics for Amphibious Rifle when Shooting Ammunition under Water}

\subsection{Features of Interior Ballistics for Amphibious Rifle when Shooting Ammuni- tion under Water}

The process of the amphibious rifle shooting effect when shooting in water is close to that of shooting in the air. Some different characteristics are as follows:

- there is water in the barrel bore,

- under the effect of propellant gas pressure, the system includes projectile and all water in the barrel is pushed out of the barrel bore. To simplify the calculation, the system can be considered as an object with a variable mass, which is calculated as the sum of the projectile mass and the actual mass of water in the barrel bore at the same time. The sum of mass varies according to the position of the object compared to the original position,

- in the shooting process, the projectile's motion is affected by a pressure, which consists of the hydrostatic pressure and the dynamic pressure. This pressure creates a drag force for projectile [4].

According to the above characteristics, the process of projectile motion in the barrel bore can be divided into two phases (Fig. 1):

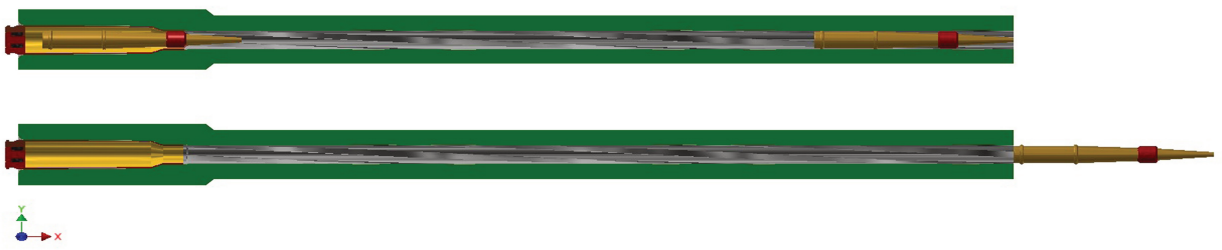

Fig. 1 Diagram of the process of the underwater projectile motion in the barrel 
Phase I. The projectile moves from its initial position until the top of the projectile reaches the muzzle cross-section. In this phase, the projectile's mass is considered as the sum of projectile mass and the actual mass of water inside the barrel bore ahead of the projectile.

Phase II. It starts when the projectile top leaves the muzzle cross-section and ends when the projectile bottom reaches the muzzle cross-section. In this phase, the actual projectile's mass is considered only.

\subsection{Mathematical Model of Interior Ballistics for Amphibious Rifle when Shooting Ammunition under Water}

In accordance with classical interior ballistic theory, the system of interior ballistic equations of the automatic weapon when firing in the air is in [5] and [6]:

$$
\begin{gathered}
\frac{\mathrm{d} z}{\mathrm{~d} t}=\frac{p}{I_{k}} \\
\psi=\chi z\left(1+\lambda z+\mu z^{2}\right) \\
S p\left(l_{\psi}+l\right)=f \omega \psi-\frac{\gamma-1}{2} \varphi m_{\mathrm{p}} v_{\mathrm{p}} \\
l_{\psi}=l_{0}\left[1-\frac{\Delta}{\delta}-\Delta\left(\alpha-\frac{1}{\delta}\right) \psi\right] \\
v_{\mathrm{p}}=\frac{\mathrm{d} l}{\mathrm{~d} t}
\end{gathered}
$$

where $\psi$ - the mass fraction of burnt powder, $\chi, \lambda, \mu$ - the shape coefficients of powder, $z$ - the relative thickness of burnt powder, $p$ - the average pressure of powder gas in the barrel, $I_{k}$ - the total pressure impulse, $S$ - the cross-section of the barrel bore, $l_{\psi}$ - the fictive length of free volume of a cartridge chamber, $l_{0}$ - the fictive length of free volume of a cartridge chamber, $l$ - the displacement of projectile inside the barrel, $f$ the specific energy of powder, $\omega$ - the mass of powder charge, $\gamma-$ the adiabatic constant, $\varphi$ - the coefficient of projectile fictitious mass, $m_{\mathrm{p}}-$ the projectile mass, $v_{\mathrm{p}}-$ the velocity of projectile, $\Delta$ - loading density of powder, $\delta$ - the powder density, $\alpha-$ the co-volume of powder gas.

Different features of interior ballistics for the amphibious rifle shooting the ammunition underwater were analysed above. So, the system of the differential equations of interior ballistic process in the amphibious rifle shooting the ammunition underwater is arranged which includes the burning rate law equation, the rate of gas formation equation which is the same as in air, the derived equation of projectile translation motion and the energy conservation equation.

\subsection{Basic Assumptions}

In order to determine the mathematical model of the interior ballistic process in the amphibious rifle shooting the ammunition underwater, the following assumptions are used:

- considering the projectile as a piston pushing water out of the barrel, there is no gas passing through the gap between the projectile and the barrel, 
- the water in barrel is not evaporated by the heat,

- water is an incompressible and viscous fluid,

- heat losses inside the barrel are neglected,

- the barrel is placed horizontally, and water is in static state (Fig. 2).

\subsection{Derivation of Equation of Projectile Translation Motion in Barrel Bore under Water}

In order to describe the projectile motion in the barrel bore underwater, the 2D orthogonal coordinate system has been used with the beginning point at the centre of the cartridge chamber bottom $O$, as it is shown in Fig. 3, where: $x$ - the axis represents the horizontal axis of the projectile symmetry. It also is the horizontal axis of the barrel; $l_{b}$ - the distance of projectile movement inside the barrel, $l_{p}$ - the length of underwater projectile; $l_{c b}$ - the length of cartridge chamber; $l$ - the displacement of projectile inside the barrel, and $l=x-\delta_{0}, p_{a}-$ the pressure at the projectile bottom.

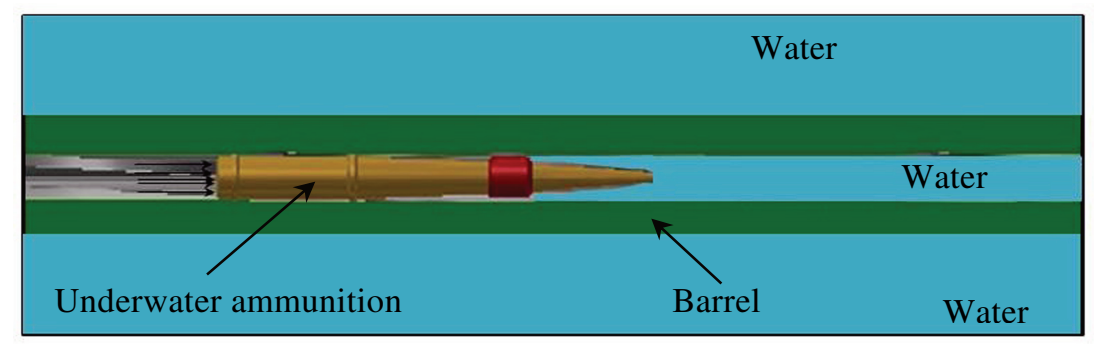

Fig. 2 View of the barrel with ammunition located in water

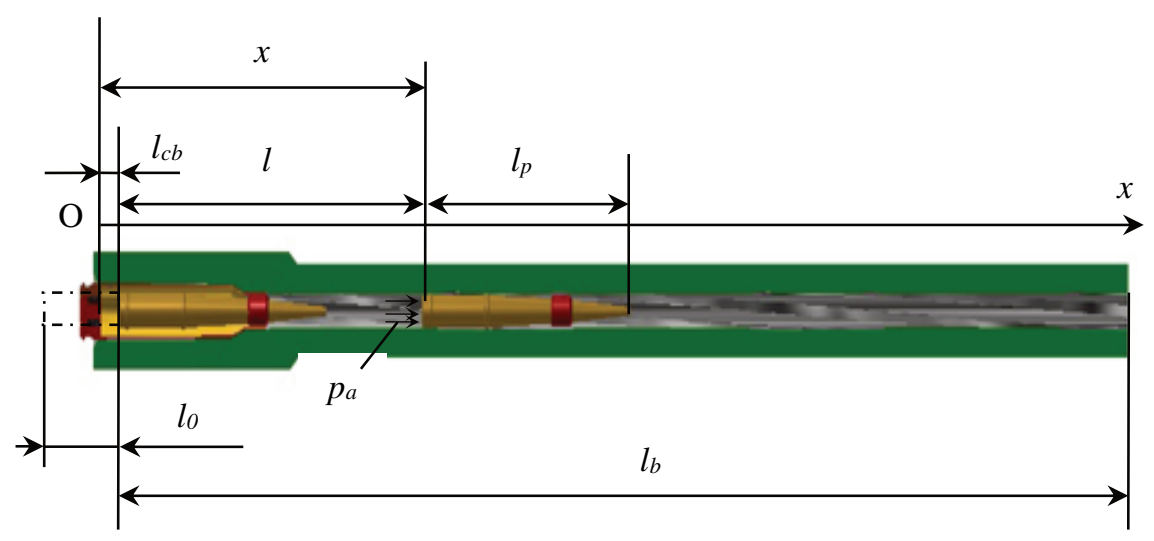

Fig. 3 Coordinate system to study underwater interior ballistics

According to the third assumption and Newton's Second Law of Motion, we can describe the motion of the projectile in the barrel bore underwater as follows:

$$
m_{\mathrm{t}} \frac{\mathrm{d} v_{\mathrm{p}}}{\mathrm{d} t}=\left(m_{\mathrm{p}}+m_{\mathrm{w}}\right) \frac{\mathrm{d} v_{\mathrm{p}}}{\mathrm{d} t}=S p_{a}-D
$$




$$
\frac{\mathrm{d} l}{\mathrm{~d} t}=v_{\mathrm{p}}
$$

where $D$ - total drag force, $m_{\mathrm{t}}$ - the total mass of the projectile, $m_{\mathrm{p}}$, and the mass of water in the barrel bore ahead of the projectile, $m_{\mathrm{w}}$, which can be calculated by form:

$$
m_{\mathrm{w}}=\rho S\left(l_{b}-l_{\mathrm{p}}-l\right)
$$

where $\rho$ - the water density;

The total drag force acting on the nose of the underwater projectile when moving in the barrel bore consists of pressure drag and friction drag as follows [7]:

$$
D=D_{\mathrm{p}}+D_{\mathrm{f}}
$$

where $D_{\mathrm{p}}$ is the pressure drag force, $D_{\mathrm{f}}$ is the friction drag force.

The pressure drag force $D_{\mathrm{p}}$ includes the drag force caused by hydrostatic pressure and the drag force caused by hydrodynamic pressure [8]. So, it can be calculated by:

$$
D_{\mathrm{p}}=\left(p_{0}+\rho g h\right) S+\frac{1}{2} \rho v_{\mathrm{p}}^{2} S
$$

where $p_{0}$ - the atmospheric pressure, $g$ - the acceleration of gravity, $h$ - the depth of water.

The friction drag force $D_{\mathrm{f}}$ is given by the formula [9]

$$
D_{\mathrm{f}}=\frac{1}{2} C_{\mathrm{f}} \rho v_{\mathrm{p}}^{2} \pi d\left(l_{b}-l_{\mathrm{p}}-l\right)
$$

where $d$ - the diameter of the bore, $C_{\mathrm{f}}$ - the skin friction coefficient. It depends on the Reynolds number $R e$ and it is calculated according to the relations introduced in Tab. 1 [10].

Tab. 1 Dependence of skin friction coefficient on the Reynolds number

\begin{tabular}{|c|c|}
\hline Reynolds number $(R e)$ & Skin friction coefficient $\left(C_{\mathrm{f}}\right)$ \\
\hline $0<R e<2300$ & $C_{\mathrm{f}}=64 / R e$ \\
\hline $2300 \leq R e<4000$ & $C_{\mathrm{f}}=2.7 / R e^{0.53}$ \\
\hline$R e \geq 4000$ & $C_{\mathrm{f}}=[1.8 \log (R e)-1.5]^{-2}$ \\
\hline
\end{tabular}

In Tab. 1, the Reynolds number is given by the formula $\operatorname{Re}=v \cdot d / \eta$, where $\eta$ is the dynamic viscosity of the fluid.

Substituting Eqs (10) and (11) into Eq. (6), we can get:

$$
\frac{\mathrm{d} v_{\mathrm{p}}}{\mathrm{d} t}=\frac{S p_{a}-\left[\left(p_{0}+\rho g h\right) S+\frac{1}{2} \rho v_{\mathrm{p}}^{2} S+\frac{1}{2} C_{\mathrm{f}} \rho v_{\mathrm{p}}^{2} \pi d\left(l_{b}-l_{p}-l\right)\right]}{m_{\mathrm{p}}+\rho S\left(l_{b}-l_{p}-l\right)}
$$

or

$$
\frac{\mathrm{d} v_{\mathrm{p}}}{\mathrm{d} t}=\frac{S p_{a}}{m_{\mathrm{t}} \varphi_{H}}
$$


where $\varphi_{H}$ is the coefficient of hydraulic losses expressed by the equation:

$$
\varphi_{H}=\frac{1}{1-\frac{\left(p_{0}+\rho g h\right) S+\frac{1}{2} \rho v_{\mathrm{p}}^{2} S+\frac{1}{2} C_{f} \rho v_{\mathrm{p}}^{2} \pi d\left(l_{b}-l_{p}-l\right)}{S p_{a}}}
$$

In addition, in dependence on the projectile position phase, the water mass in the bore and the total drag change. This change is shown in Tab. 2 .

Further, it is necessary to determine the pressure at the projectile bottom $p_{a}$. At a distance $x$ from the bottom of the cartridge chamber bottom under conditions that the projectile bottom is in the position $l$ and its acceleration is $\mathrm{d} v_{\mathrm{p}} / \mathrm{d} t$, and using Newton's Second Law for a gas element $\mathrm{d} x$, we have (Fig. 4).

Tab. 2 Change of the water mass in the barrel bore and the total drag during projectile motion in the barrel bore

\begin{tabular}{|c|c|c|}
\hline Phase of motion & $\begin{array}{c}\text { Total mass of underwa- } \\
\text { ter projectile and water }\end{array}$ & Total drag force \\
\hline $\begin{array}{c}\text { Phase I } \\
{\left[0 \leq l \leq\left(l_{b}-l_{\mathrm{p}}\right)\right]}\end{array}$ & $m_{\mathrm{t}}=m_{\mathrm{p}}+\rho S\left(l_{b}-l_{\mathrm{p}}-l\right)$ & $D=\left(p_{0}+\rho g h\right) S+\frac{1}{2} \rho v_{\mathrm{p}}^{2} S+$ \\
& $+\frac{1}{2} C_{\mathrm{f}} \rho v_{p}^{2} \pi d\left(l_{b}-l_{\mathrm{p}}-l\right)$ \\
\hline $\begin{array}{c}\text { Phase II } \\
{\left[\left(l_{b}-l_{p}\right)<l=l_{b}\right]}\end{array}$ & $m_{\mathrm{t}}=m_{\mathrm{p}}$ & $D=D_{\mathrm{p}}=\left(p_{0}+\rho g h\right) S+$ \\
$+\frac{1}{2} \rho v_{\mathrm{p}}^{2} S$
\end{tabular}

$$
S p_{x}-S\left(p_{x}+\frac{\partial p_{x}}{\partial x} d x\right)=S \rho_{x} \mathrm{~d} x \frac{\mathrm{d} v_{x}}{\mathrm{~d} t}
$$

or

$$
\frac{1}{\rho_{x}} \frac{\partial p_{x}}{\partial x}=-\frac{\mathrm{d} v_{x}}{\mathrm{~d} t}
$$

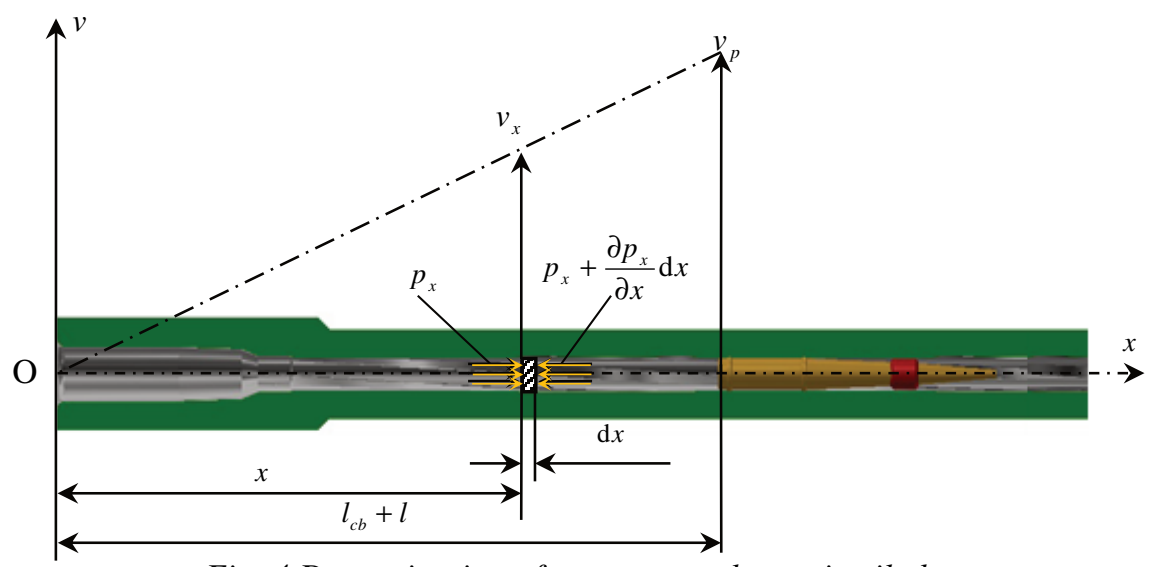

Fig. 4 Determination of pressure at the projectile bottom 
The gas density $\rho_{x}$ is given by the following equation:

$$
\rho_{x}=\frac{\omega}{S\left(l_{c b}+l\right)}
$$

where $l_{c b}$ is the length of the cartridge chamber. follows:

The equation determining pressure $p_{x}$ is derived [6] and the resulting form is as

$$
p_{x}=p_{a}\left[1+\frac{\omega}{2 \varphi_{H} m_{\mathrm{t}}}\left(1-\frac{x^{2}}{\left(l_{c b}+l\right)^{2}}\right)\right]
$$

Thus, we can determine the average pressure of powder gas in the barrel $p$ as:

$$
p=\frac{1}{l_{c b}+l} \int_{0}^{l_{b d}+l} p_{x} \mathrm{~d} x=p_{a}\left(1+\frac{1}{3} \frac{\omega}{\varphi_{H} m_{\mathrm{t}}}\right)
$$

According to the Eqs (12), (16) and (19), we can rewrite the system of equations describing the motion of underwater projectile in the barrel to the form:

$$
\frac{\mathrm{d} v_{\mathrm{p}}}{\mathrm{d} t}=\frac{S \frac{p}{\left(1+\frac{1}{3} \frac{\omega}{\varphi_{H} m_{\mathrm{t}}}\right)}-D}{m_{\mathrm{t}}}
$$

\subsection{Energy Conservation Equation for Amphibious Rifle Firing Ammunition under Water}

Based on the energy equation in the air [6], we can rewrite it for the case of firing the projectile underwater:

$$
S p\left(l_{\psi}+l\right)=f \omega \psi-(\gamma-1) \sum_{i=1}^{n} W_{i}
$$

where $\sum_{i=1}^{n} W_{i}$ is the sum of external work that is divided into 5 parts as follows:

- the kinetic energy of the projectile:

$$
W_{1}=\frac{1}{2} m_{\mathrm{p}} v_{\mathrm{p}}^{2}
$$

- the kinetic energy of the water ahead of the projectile in the barrel bore:

$$
W_{2}=\frac{1}{2} m_{\mathrm{w}} v_{\mathrm{p}}^{2}=\frac{1}{2} \rho S\left(l_{b}-l_{p}-l\right) v_{\mathrm{p}}^{2}
$$

- the kinetic energy of the water ejected from the barrel muzzle:

$$
W_{3}=\int_{0}^{l_{b}-l_{p}} \frac{\rho v^{2} S}{2} \mathrm{~d} l
$$

- the energy to overcome the resistant forces: 


$$
W_{4}=\int_{0}^{l_{b}-l_{\mathrm{p}}} D \mathrm{~d} l
$$

- the kinetic energy of gas and unburnt powder:

$$
W_{5}=\frac{\omega}{6} v_{\mathrm{p}}^{2}
$$

Eqs (1), (2), (5), (20) and (21) form the system of differential equations for interior ballistic of the amphibious rifle shooting the ammunition underwater as follows:

$$
\left\{\begin{array}{l}
\frac{\mathrm{d} z}{\mathrm{~d} t}=\frac{p}{I_{k}} \\
\psi=\chi z\left(1+\lambda z+\mu z^{2}\right) \\
\frac{\mathrm{d} l}{\mathrm{~d} t}=v_{\mathrm{p}} \\
\frac{\mathrm{d} v_{\mathrm{p}}}{\mathrm{d} t}=\frac{\left(1+\frac{1}{3} \frac{\omega}{\varphi_{H} m_{\mathrm{t}}}\right)}{m_{\mathrm{t}}}-D \\
S p\left(l_{\psi}+l\right)=f \omega \psi-(\gamma-1) \sum_{i=1}^{5} W_{i}
\end{array}\right.
$$

\section{Validation of Model}

\subsection{Applying Model for Investigating Dependence of Underwater Interior Ballistic Processes on Powder Mass for $5.56 \mathrm{~mm}$ Underwater Ammunition}

The mathematical model of interior ballistics derived above is applied for the $5.56 \mathrm{~mm}$ underwater ammunition which is shot from the $5.56 \mathrm{~mm}$ amphibious rifle. Some basic parameters of $5.56 \mathrm{~mm}$ underwater ammunition are shown in Fig. 5.

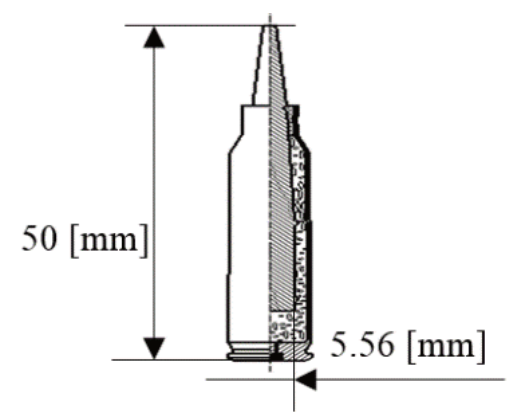

Fig. 5 Basic parameters of $5.56 \mathrm{~mm}$ underwater ammunition

The cases of investigation are shown as Tab. 3 .

The main input parameters to solve the mathematical model of interior ballistics are given in Tab. 4 . 
Tab. 3 Cases of investigation

\begin{tabular}{|c|c|c|c|c|c|}
\hline $\begin{array}{c}\text { Cases of } \\
\text { investigation }\end{array}$ & $\begin{array}{c}\text { Material } \\
\text { of } \\
\text { projectile }\end{array}$ & $\begin{array}{c}\text { Mass of } \\
\text { projectile } \\
{[\mathrm{g}]}\end{array}$ & $\begin{array}{l}\text { The distance } \\
\text { of projectile } \\
\text { motion [m] }\end{array}$ & \multicolumn{2}{|c|}{$\begin{array}{c}\text { Mass of powder } \\
{[\mathrm{g}]}\end{array}$} \\
\hline \multirow{4}{*}{ Case 1} & \multirow{4}{*}{ Bronze } & \multirow{4}{*}{6.8} & \multirow{4}{*}{0.408} & Type A & 0.5 \\
\hline & & & & Type B & 0.55 \\
\hline & & & & Type C & 0.6 \\
\hline & & & & Type D & 0.65 \\
\hline \multirow{4}{*}{ Case 2} & \multirow{4}{*}{$\begin{array}{l}\text { Tungsten } \\
\text { carbide }\end{array}$} & \multirow{4}{*}{13.7} & \multirow{4}{*}{0.408} & Type A & 0.5 \\
\hline & & & & Type B & 0.55 \\
\hline & & & & Type C & 0.6 \\
\hline & & & & Type D & 0.65 \\
\hline
\end{tabular}

Tab. 4 Main input parameters for solution

\begin{tabular}{|c|c|c|}
\hline Notation & Parameters & Value \\
\hline$d$ & Calibre of gun & $0.00556 \mathrm{~m}$ \\
\hline$l_{\mathrm{p}}$ & Cartridge chamber volume & $1.65 \times 10^{-6} \mathrm{~m}^{3}$ \\
\hline$g$ & Length of projectile & $50 \mathrm{~mm}$ \\
\hline$\rho$ & Acceleration of gravity & $9.81 \mathrm{~m} / \mathrm{s}^{2}$ \\
\hline$h$ & Density of water & $1000 \mathrm{~kg} / \mathrm{m}^{3}$ \\
\hline$p_{\text {atm }}$ & Depth of the firing position & $1 \mathrm{~m}$ \\
\hline$\eta$ & Atmospheric pressure & $101325 \mathrm{~Pa}$ \\
\hline & Dynamic viscosity of water at $25^{\circ} \mathrm{C}$ & $0.00089 \mathrm{~Pa} \cdot \mathrm{s}$ \\
\hline
\end{tabular}

The system of differential equations for underwater interior ballistic (Eq. (27)) has been solved using the $4^{\text {th }}$ order Runge-Kutta integration method and the MATLAB programming environment. Selected results of solution are presented in Fig. 6 and Fig. 7.

The figures show: the air,

- the underwater ballistic curves have a shape similar to the ballistic curves in

- when the powder mass increases, the pressure curve and the velocity curve of the ammunition rise. This is because the burning process becomes more intense. 

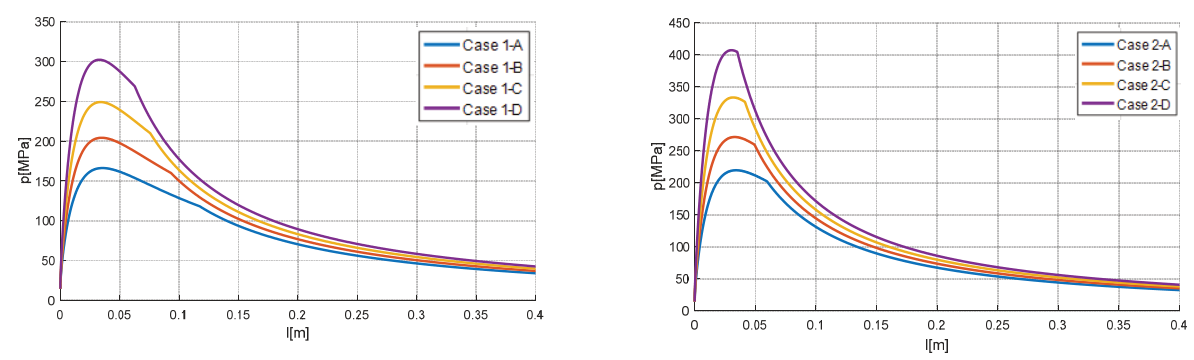

Fig. 6 Pressure vs. trajectory of the projectile
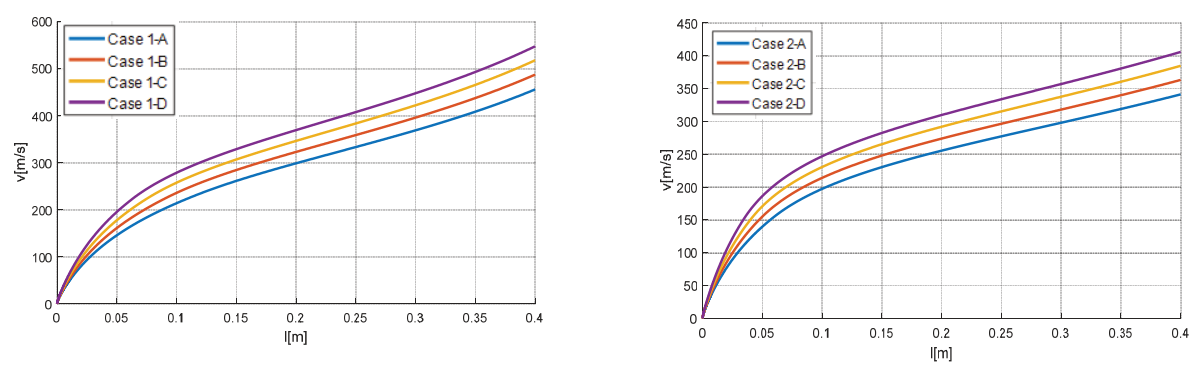

Fig. 7 Muzzle velocity vs. trajectory of the projectile

\subsection{Experiments Determining Ballistic Parameters for $5.56 \mathrm{~mm}$ Underwater Am- munition for Verifying Mathematical Model}

The purpose of the experimentation is to verify the mathematical model mentioned. The measured ballistic parameters are the maximum pressure in the barrel and the muzzle velocity corresponding to the powder mass.

The experiments were carried out in the Weapon Technology Center of the Le Quy Don Technical University in Hanoi. The Crusher gauge is used to determine the pressure maximum, while the high-speed camera system is used to measure the muzzle velocity. The diagram of the experimental setup is shown in Fig. 8.

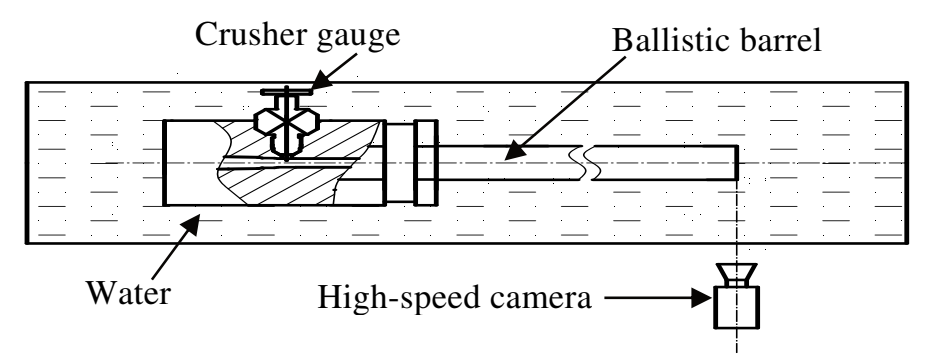

Fig. 8 Schematic of the experimental setup

\subsection{Results and Discussion}

The comparison between the calculation results and the experimental results corresponding to the two cases of the ammunition is shown in Figs 9 and 10. 

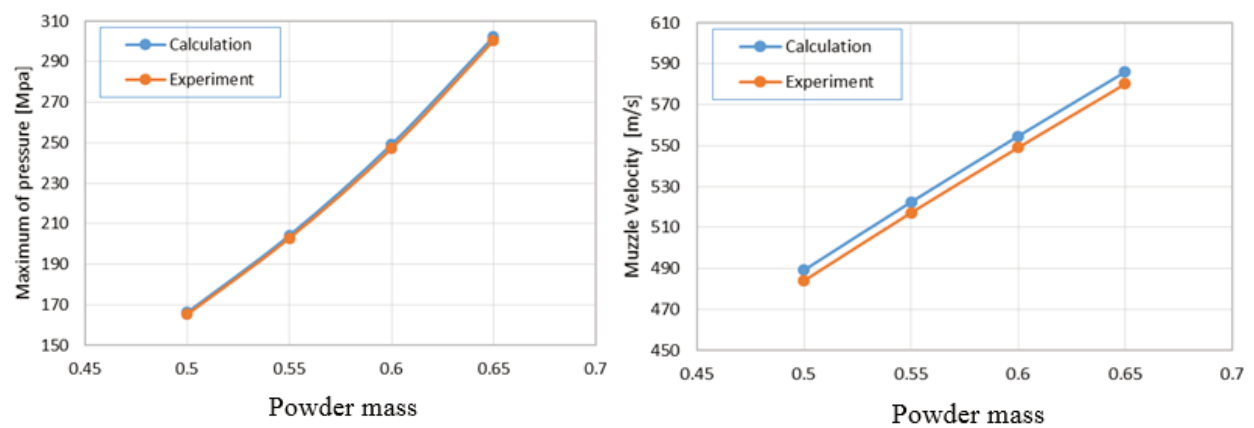

Fig. 9 Dependence of maximum pressure and muzzle velocity on powder mass (Case 1: Projectile mass is $6.8 \mathrm{~g}$ )
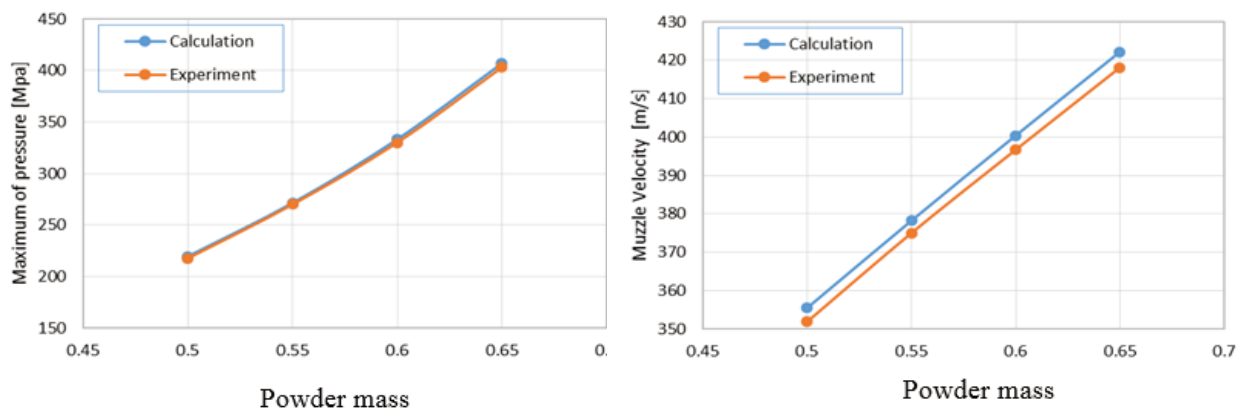

Fig. 10 Dependence of maximum pressure and muzzle velocity on powder mass

(Case 2: Projectile mass is $13.7 \mathrm{~g}$ )

The comparisons show a very good agreement between the results of calculation and experimental results in investigating the dependence of the underwater interior ballistic processes on the powder mass for the $5.56 \mathrm{~mm}$ underwater ammunition. The muzzle velocity in the theoretical results is higher than the experimental results due to ignoring the heat losses of the powder gas.

\section{Conclusion}

The article presents the mathematical model of interior ballistics for the amphibious rifle when shooting the underwater ammunition. The dependence of the underwater interior ballistics processes on the powder mass was investigated when some $5.56 \mathrm{~mm}$ ammunition types were shot underwater.

The comparison of theoretical and experimental results shows very good accuracy and capability of the model. The accepted assumptions and adaptations of the general mathematical model of interior ballistics for the water environment are proven to be correct and acceptable. These results may be utilised in the design process of the underwater ammunition and amphibious rifle. 


\section{Acknowledgment}

The work presented in this paper has been supported by the Weapon Technology Centre and Faculty of Weapons, Le Quy Don Technical University in Hanoi and by the research project of the Ministry of Defense.

\section{References}

[1] MEGHAN, N. Russia's New Underwater Assault Rifle Can Shoot 800 Shots per Minute [online]. October 2013 [viewed 2019-11-15]. Available from: https://www.vice.com/en_us/article/d73g8v/russia-just-unveiled-itsamphibian-underwater-gun

[2] NGUYEN, S.H., TRAN V.T. and TRAN, T.H. On the Interior Ballistics of an Underwater Personal Gun. Vietnam Journal of Mechanics, 2016, vol. 38, no. 3, p. 215-222. DOI 10.15625/0866-7136/38/3/7483.

[3] CARLUCCI, D.E. and JACOBSON, S.S. Ballistics. Theory and Design of Guns and Ammunition. $2^{\text {nd }}$ ed. New York: CRC Press, 2013. 608 p. ISBN 978-1-4665-6439-8.

[4] GRADY, R.J. Hydroballistics Design Handbook [Technical Report No. SEAHAC/79-1]. Washington: Naval Sea Systems Command Hydromechanics Committee, 1979. 600 p.

[5] VASILE, T. Contributions to the Fundamental Problem Solving of Interior Ballistics. In Proceedings of the $2^{\text {nd }}$ International Conference Artillery Barrel Systems, Ammunition, Means of Artillery Reconnaissance and Fire Control. Kiev, 1998, p. 440-445.

[6] VASILE, T. Studies and Researches Regarding the Fundamental Problem Solving of Interior Ballistics for Weapon with Grooved Barrel. In Proceedings of the $3^{\text {rd }}$ International Armament Conference on Scientific Aspect of Armament Technology. Waplewo, 2000, p. 157-165.

[7] MUNSON, B.R., YOUNG, D.F. and OKIISHI, T.H. Fundamentals of Fluid Mechanics. Hoboken: Wiley, 2006. 766 p. ISBN 978-0-470-06722-5.

[8] ANDERSON, J.D. Jr. Fundamentals of Aerodynamics, $2^{\text {nd }}$ ed. New York: McGraw-Hill Higher Education, 1990. 1131 p. ISBN 978-0-0700-1679-8.

[9] MURMAN, S.M. Lift and Drag Behavior of Unconstrained Bluff Bodies [online]. 2010. 13 p. [viewed 2019-11-14]. Available from: https://pdfs. semanticschoar.org/f629/bc5d21448e8a03a93a817ddca5d73059a7fb.pdf?_ga $=2.253886920 .1985585763 .1584041599-1139765700.1558626705$

[10] BLEVINS, R.D. Applied Fluid Dynamics Handbook. Melbourne: Krieger Publishing Company, 2003. 570 p. ISBN 978-1-57-524182-1. 